\title{
I.-SECCION DOCTRINAL
}

\section{La nueva Ley sobre el Procedimiento administrativo}

\author{
por \\ FERNANDO GARRIDO FALLA \\ Catedrático de Derecho Administrativo
}

I. LA LEGISLACIÓN ADMINISTRATIVA DE CARÁCTER GENERAL

1. Nuestro Derecho administrativo positivo se ha visto enniquecido durante los últimos años con tres importantísimas leyes de carácter general: la Ley sobre Expropiación forzosa de 16 de diciembre de 1954, la Ley sobre la Jurisdicción contenciosoadministrativa de 27 de idiciembre de 1956 y la Ley de Régimen jurídico de la Administración pública, texto refundido de 26 de julio de 1957. La simple comprobación de la proximidad cronológica de estas tres leyes, debe considerarse ya como un indicio revelador de que nos encontrábamos en un momento en que se disponía de la técnica y la acometividad neceslarias para lograr una revisión a fondo ide nuestro Ordenamiento juríficoadministrativo. Pero obsérvese, ante todo, que lo que aquí subrayamos no es tanto el hecho de que nuestra legislación administrativa sea actualmiente frondosa-cosa, por otra parte, nada merecedora de elogio-cuanto el hecho de que lasi elaboradas sean cabalmente leyes administrativas de carácter general.

De siempre se ha planteado la doctrina administrativa la gran cuestión de la posibilidad de codlificar esta rama del Derecho. Muy bien pudieræ ocurrir que, frente a la utopia del Código 
administrativo, la solución estuviese en unas cuantas leyes generales; aun cuando tampoco deba descartarse la posibilidad de que esto constituya justamente el primer paso serio hacia tal codificación. En cualquier caso, lo que resulta alentador es descubrir el elevado aliento técnico y doctrinal que informa cada una de las antes citadas leyes, en las que las necesidades de la práctica se han combinado adecuadamente con la dogmática jurídico-administrativa, habiéndose venido a demostrar, una vez más, la conveniencia de que el legislador cuente en primera fila con la doctrina científica. Como ha dicho Cataldi, con referencia ail mismo problema tal como está planteado en Italia: "La doctrina no debe ser relegada en adelante al campo de los ejercicios teónicos; debe salir del claustro y debe invadir el campo del Derecho positivo, no para interpretarlo, sino para determinarlon (1).

2. El simple anuncio de que el Gobierno iba a enviar a las Cortes un proyecto de Ley sobre el Procedimiento administrativo, nos hizo pensar inmediatamente en que el camino iniciado por la Ley de Régimen jurídico de la Administración pública iba a andarse hasta el final. En efecto, el ambicioso título de aquella Ley parecía ofrecer un contenido que luego quedaba un tanto mutilado en la realidad. Régimen jurídico constituye, desde luego, todos y cada uno de los preceptos que en los distintos capítulos de esa Ley se contienen; pero también son Régimen jurídico otras materias que no fueron abordadas por la Ley y entre ellas, y notoriamente, está el Procedimiento adiministrativo. Sobre todo si se tiene en cuenta que el proyecto redactado por el Gobierno era ciertamente ambicioso y no se limitaba, desde luego, al simple aspecto procedimental de la acción administrativa. Creo, por ello, que la nueva Jey de Procedimiento debió concebirse como complementaria de la de Régimen jurídico, y destinada a fundirse con ella. No sólo no existían dificultades, sino que, por el contrario, hubiese sido factible

i (1) CATALDI, La legge generale sullazione amministrativa e le altre leggi generali amministrative, en aRivista Trimestrale di Diritto Publicon, 19å, núm. 2, piig. 471. 
y muy conveniente, que la nueva Ley hubiese inciuido una cláusula que habilitase al Gobierno para dictar un nuevo texto refundido, incorporando ésta a la Ley de Régimen juridico. Basta comparar los títulos y capítulos de cada una de estas leyes para comprender su correspondencia sistemática $\mathrm{y}$, consiguientemente, la posibilidad de reconducirlas a un texto legal único. Esta nueva y amplia Ley se parecería mucho, por su contenido, ai primer proyecto de Ley genoral sobre la acción administrativa que redactó la Comisión para la Reforma de la Administración en Italia, y que se componía de los siguientes títulos: de las Administraciones públicas, del Procedimiento administrativo, del Acto administrativo, de la Revisión de los actos administrativos, y de la Responsabilidad de las Administraciones públicas (2).

\section{La REgUlación DEL PROCEDIMIENTO ADMINISTRATIVO}

3. No se ha puesto suficientemente de relieve por nuestra doctrina la peculiaridad que significa, desde el punto de vista del Dérecho comparado, el hecho de que entre nosotros el procedimiento administrativo sea una materia legalmente regulada. Esta peculiaridad es tanto más notable, si se tiene en cuenta la inspiración teórica que siempre hemos recibido del Derecho francés en el que, sin embargo, el: tema del procedimiento administrativo nunca ha preocupado al legislador. Como ha puesto de relieve Langrod, 1a noción del acto administrativo ha llegado

(2) Catıldr, op. cit., pág. 45̄3. Con anterioridad se habia preparado en Italia un amplísimo esquema de Ley general sobre Administración pública (casi un verdadero (Código administrativo), debido en los siguientes titulos: I. Las fuentes (con el régimen juridics de los reglamentos y demás disposiciones administrativas generales). II. El ciudadano y la Administración (con el régimen de las prestaciones de los servicios públicos, del uso de los bienes demaniales e incluso el proceciimiento administrativo y lo contenciosn-adnuinistrativo). III. Los actos admi9istrativas (caracteres y vicios). IV. La responsabilidad de la Administración (incluida la de los funcionarios). V. Los entes morales (nacimiento, régimen y extinción). V.I. La policía administrativa (principios que rigen las linitaciones impuestas a la actividad privada). 
a absorber y nublar todo el proceso de su creación progresiva, todas esas operaciones preparatorias que deben precederle fatalmente para que tome cuerpo; según esta óptica particular, el acto administrativo parece "surgir de la nada", aparece de golpe como Deux ex machina, como producto prefabricado, sin que su "devenir" atraiga la atención de la doctrina (3).

El: autor antes citado, realiza un estudio comparativo de las soluciones legislativas que los diferentes países han dado al problema del procedimiento administrativo. $\mathrm{Y}$ distingue tres grupos fundamentales :

\section{A) Paises sin Derecho administrativo procedimental.}

Es el caso antes aludido de Francia. Las preocupaciones teóricas (salvo algún genial atisbo de Hauriou), legislativas y jurisprudenciales se refieren pura y simplemente al Derecho administrativo material. De aquí se derivan importantes consecuencias prácticas: así, la publicidad del procedimiento (el trámite de vista en nuestra terminología), solamente se da si hay una expresa disposición legislativa que en la materia en cuestión lo imponga; asimismo, si bien es cierto que la jurisprudencia del Consejo de Estado ha venido a consagrar en ciertos casos, y por aplicación de un principio general del Derecho, la regla audi et alteram partem, también lo es que su campo de aplicación es limitado (4). Se ha querido justificar esta situación con el argumento de no entorpecer ni retrasar la actividad administrativa, pero en el fondo-observa Langrod-se trata de una obstinada miopía en cuanto a la visión "procedimental". Por supuesto que no tendremos que añadir que la discusión teónica acerca de la diferenciación entre el procedimiento administrativo y el Derecho procesal administrativo-tan evolucionada entre nosotros (5)es absolutamentie desconocida en el país vecino: el propio Lan-

(3) G. LANGrod, Procédure adıninistrative et Droit administratif, "Revue lnternationale des Sciences Administrativesn, sept. 19066, pág. 11.

(4) LANGRod, op. cit., pág. 32.

(5) Cfr. Gonzílez PÉRez, Tratado de Derecho procesal administrativo, vol. I. 
grod emplea en el trabajo a que nos estamos refiriendo una terminología rigurosamente indiferenciada.

En este grupo de países se puede incluir también a Alemania, si bien debe de reconocerse que algún moderno sector doctrinal admite la distinción entre un "Derecho administrativo" y un "Derecho administrativo formal o de procedimiento" (Verfahrensrecht) (6).

B) Paises que han adoptado soluciones intermedias.

Es característica de estos sistemas que en aquellos casos en que, aún tratándose de la resolución de cu'estiones típicamente administrativas, un particular aparece directamente interesado, adquiere una situación de "parte" semejante, por sus consecuencias, a la regulada por el Derecho procesal judicial. Esto es particularmente cierto en relación con la tramitación de los recursos en vía gubernativa.

Para Langrod, a quien seguimos, debe de incluirse en este grupo el sistema inglés. La llamada Administrative Justice supone cabalmente la resolución de cuestiones administrativas por organismois que desarrollan funciones cuasi-judiciales (quasijudicial pozvers) y que incluso reciben el nombre de tribunales (Administrative Tribunals) (7).

En este mismo grupo, incluye Langrod una serie de países continentales que contrastan, sin embargo, con el caso de Inglaterra, porque su característica es, no tanto una mera actitud pragmática en cuanto a la aceptación de ciertas reglas procedimentales, cuanto una cierta posición intelectual de aceptación consciente del Derecho procedimental administrativo (8). Aquí incluye en primera línea, a España y a los países sudamericanos por ella influidos; después, a Portugal, Suecia e Italia.

(6) Vid. Forsthoff, Lehrbuch des Verwalfungsrscht, 19501.

(7) Vid. López Rodó, Justicia y Administración en el Reino Unido, Madrid, 1958.

(8) Op. cit., pág. 42. 
C) Paises donde existe un Derecho administrativo procedimental.

Aquí incluye Langrod, de una parte, un grupo de países de la Europa central y oriental, a la cabeza de losi cuales se halla Austria, y, de otra, el reciente sistema de los Estados Unidos de América.

Por lo que se nefiere al primer grupo de países, se caracterizan por la existencia de un cuadro legislativo, jurisprudencial y doctrinal completo. Junto a los códigos de procedimiento judicial, existen allí textos legislativos codificados que reglan enteramente el procedimiento administrativo. Esta codificación ha sido posible gracias a la obra jurisprudencial realizada entre $\mathbf{1 8 7 5}$ y 1925 por el Tribunal Administrativo ide Viena, que, para muchos, no cede en importancia a la realizada por el Consejo de Estado francés. A través del control a posteriori de los vicios de forma-y subrayo este dato por las analogías que presenta con la labor jurisprudenciai de nuestro Tribunal Supremo-, ha surgido una jurisprudencia que hizo teóricamente posible la Ley de Procedimiento administrativo de 22-X-1925. Hay que notar que el procedimiento administrativo austríaco está fundamentalmente inspirado en una idea de protección procesal de los derechos subjetivos de los administrados (9). Pero esto no obsta, sin embargo, a que esté presente en todo caso la finalida:d de interés público perseguida por todo procedimiento administrativo $y$ que puede fundamentar consecuencias que incluso resultan avanzadas y discutibles para nuestra mentalidad en esta materia: por ejemplo, la posibilidad de la reformatio in peius por consecuencia de un recurso interpuesto por un particular contra un acto administrativo (10).

La codificación austríaca de 1925 comprende tanto el pro-

(9) LANGROD, op. cit., pág. 53. Entre n๖sotros el aprocedimiento administrativo como gatantia juridica de los administrados ha sido estudiado por Royo-Villanova.

(10) Nuestra jurisdicción de agravios se mostró expresamente contraria a esta posibilidad. 
cedimiento administrativo general, como el procedimiento de ejecución, así como el disciplinario. Su influencia fué decisiva en los países vecinos y así, de acuerdo con el modelo austríaco, se dictaron nuevos códigos de procedimiento: 1) En Checoslovaquia, el Reglamento de 13 de enero de 1928. 2) En Pollonia, el Reglamento de 22 de marzo de 1928 (ulteriormente modificado en 1934 y en 1938). 3) Finalmente, en Yugoslavia, la Ley de 9 de noviembre de 1930 .

Es curioso señalar que esta conquista jurídica arraigó de tal forma en los países mencionados, que sus principios básicos han podido sobrevivir en clima tan notoriamente adverso como el producido por los regímenes comunistas de Checoslovaquia, Polonia y Yugoslavia (11). Máxime si se tiene en cuenta que nada parecido conoce el Derecho soviético-del cual reciben estos países las principales influencias-, donde el control de la legalidad de la actuación administrativa está en manos de un órgano estrictamente gubernativo dependiente directamente del Soviet Supremo: la "Prokuratura" o Fiscalía general (12). Y no solamente permanecen los viejos principios-aunque se tienda a acomodarlos a un "espíritu nuevo" que convierte a ios particulares de "partes" en "cooperadores" de la acción administrativa-en aquellos paises donde ha habido una derogación formal de la antigua Ley, como es el caso de Polonia, sino que también continúa en las nuevas reglamentaciones, como la dictada por el Gobierno de Checoslovaquia en 22 de marzo de 1955. En reciente trabajo publicado por el profesor polaco Iserzon sobre la reforma del procedimiento administrativo en Polonia (13), se señalan los siguientes postulados sobre losı que debe basarse la revisión del Código polaco de Procedimiento: $10^{\circ}$ El Código no debe aplicarse más

(11) Vid. Langrod, op. cit., pág. īs; y del mismo, Les traits essentiels de l'Administration publique en régime communuste, en wLa Revue Administrative», núm. 22, 1951, págs. 423 y siguientes.

(12) D. A. LOEBER, La aProkuratura» sciriética y los derechos del individuo bacia el Estado, en «Revista de ia Comisión Internacional de Juristas», Ja Haya, núm. 1, otoño de 1957 , págs. 63 y siguientes.

(13) La réforme de la procédure administrative non contentieuse en Pologne, ¿n ERevista Internacional de Ciencias administrativas», 1958, núm. 1, págs. 21 y ss. 
que a los actos administrativos que decidan sobre derechos u obligaciones de los particulares (es decir, añade este autor, ejercicio de la "función jurisdiccional" de la Administración). 2. Debe mantenerse el principio de lá audiencia oral' en aquellos casos en que así esté prescrito para una categoría dada de asuntos ardministrativos o se pueda conseguir sensiblemente la aceleración o simplificación de un procedimiento. $3 .^{\circ}$ Las reglas procedimentales deben aplicarse a la actividad de tos organismos autónomos. $4 .^{\circ}$ No debe haber sectores de la actividad administrativa excluídos de la aplicación del Código. Asimismo, se refiere más adelante Iserzon a la necesidad de motivar los actos administrativos y al principio de publicidad del procedimiento. Como se ve, se trata de extremos en los que coincidiría sin reparo cualquier jurista del viejo sistema "capitailista y burgués".

Aunque con caracteres completamente distintos, se incluye también en este grupo la codificación del procedimiento administrativo realizada por la Federal Administrative Procedure Act. de 11 de junio de 1946. No son pocos los obstáculos que ha habido que vencer para lograr un Código de este tipo en un país dunde el Derecho administrativo apenas si ha sido e.aborado y donde todo intento de poner trabas a los procedimientos de la Administración-alli donde el ejemplo óptimo a seguir es la actuación de la empresa privada-ha sido calificado como el "sabotaje idel procedimiento administrativon (14). Pero, a pesar de todo, ahí está esa amplia Ley de 1946, en la que se regu'a tanto el procedimiento para dictar reglamentos administrativos, como el que precede a la resolución de expedientes contradictorios ( $A d j u$ dications), como, finalmente, el relativo al control judicial de la Administración (15).

4. Creo. discrepando de Langrod, que el Derecho admin:strativo procedimental es en España por lo menos tan importante

(14) F. W. Blachly y M. E. OAtman, Sabotage of the administrative frocedure, en a Public Administration Reviews, 1946, núm. 6, págs. 213 y ss. Cit. por Langrod, op. cit., pág. 63, por nota.

(15) Vid. TRISTÁN Bochs, El procedimiento administrativo en los Estados Unidos, Montevideo, 1953. 
como en cualquiera de los países incluídos en el último de los grupos examinados. Adviértase, por de pronto, en apoyo de esta afirmación, el hecho innegable de la primacía cronológica de nuestra legislación sobre la materia. Aparte otros precedentes que pudieran ser invocados, el 19 de octubre de 1889 se promulgó la Ley de Bases a la que habían de ajustarse los reglamentos de procedimiento administrativo en los distintos Departamentos ministeriales. Ya el dato de esta fecha sería bastante a disculpar ciertos defectos técnicos que pudiésemos descubrir hoy, casi tres cuartos de siglo después.

Pero es que nuestro Derecho administrativo procedimental no estaba constituído solamente por la Ley de Bases de 1889 y las escasas disposiciones reglamentarias que se dictaron en el ingenuo y a todas luces insuficiente plazo de seis meses que en aquella se señalara (16). Inspirándose lejanamente en aquellas Bases, pero respondiendo a preocupaciones surgidas en épocas muy posteriores, se han dictado amplios y detallados reglamentos, como e: de 'a Subsecretaría de Gracia y Justicia de 1917, el del Ministerio de la Gobernación de 1947, el del Ministerio de Comercio de 1951 o los todavía más recientes de Industria y de Trabajo de 19.51 ; esto sin contar el detalladisimo y cuasi-judicial procedimiento establecido para las reclamaciones económico-administrativas por Real Decreto de 29 de julio de 1924.

A esto hay que unir, para completar el cuadro, la obra de nuestra jurisprudencia contencioso-administrativa. A: margen del recurso de p'ena jurisdicción establecido en el artículo $1 .^{\circ}$ de la Ley de la Jurisdicción contencioso-administrativa de 1894, el Tribuna! Supremo ha venido configurando un recurso de anulación por "vicios de procedimiento". No es el caso de examinar

(16) Si realizamos el cómputo del plazs cor una cierta generosidad, nos encontrámos con las siguientes disposiciones dictadas de acuerdo con lo previsto en la Lley: Reglámento del Ministerio de Estado (o Asuntos Exteriores) de $\mathbf{1 7}$ de abril de $1 \$ \varsigma 50$; Reglamento del Ministerio de la Gobernación y Dependencias provinciales y locales del mismo, de 22 de abril de 1890; Reglamento del Ministerio de Fomento (aplicable a Obras Públicas), de 23 de al,ril de 1890 ; Reglamento dei Minister:o de la Guerra de 25 de abril de 1890 , y, de la misma fecha que el ariterior, Reglamento del Ministerio de Marina. 
ahora el alcance de tal doctrina jurisprudencial ; bástenos simplemente recordar: $1 .^{\circ}$ Que nuestro Tribunal Supremo ha exigido rigurosamente el cumplimiento de los trámites procedimentales establecidos, tanto en interés de los derechos de los particulares, como en interés público; es' reiteradísima la doctrina jurisprudencial de que "la normas procedimentales son de orden públicon. 2. En especial ciertos trámites como el de vista del expediente y audiencia del interesado, se han considerado siempre por el Tribunal Supremo como requisitos esenciales del procedimiento cuando la resolución del mismo implique perjuicio a los derechos de los particulares interesados (17).

Finalmente, la consitrucción doctrina! de nuestro Derecho administrativo procedimental también es importante. Baste recordar en estos momentos los nombres de Gascón y Marín (18), RoyoVillanova (19), Villar y Romero (20), López Rodó (21), AmorósRica (22) y González Pérez (23).

5. De las consideraciones que acabamos de hacer en relación con nuestro Derecho, no debe deducirse, ni con mucho, que el estado legislativo fuese satisfactorio. Una cosa es que tuviésemos un Derecho administrativo procedimental importante, y otra que tal Derecho fuese perfecto.

La principal objeción que podía hacerse era la de la falta de unidad. Al ser la de 1889 una Ley de Bases, el desarrollo reglamentario ulterior a cargo de los distintos Ministerios había conducido paradójicamente a soluciones tan contradictorias entre sí

(17) Vid. Serrano Guirado, El trámite de audiencia en el procedimiento administrativo, en «Revista de Administración Públican, núm. 4, 1951, págs. 120 ss., y la jurisprudencia que alli se cita.

(18) Necesidad de un Código de Procedimiento administrativo, en Revista de Estudios Politicos», núm. 48, 1949, págs. 11 y ss.

(19) El Procedimiento administrativo como garantia juridica, en e.Revista de Estudios Politicosn, núm. 48, 1949, págs. $5 \overline{5}$ y ss.

(20) Derecho procesal administrativo, Madrid, 1944.

(21) El Procedimiento administrativo en España, en ๔O Dlreito», núm. B1. págs. $27 \overline{\text { y }}$ y ss.

(22) El Procedimiento administrativo español, en aRevista General de Legiq Jación y Jurisprudencià, págs. $\cos$ y ss.

(29) Derecho procesal administrativo, tomo I, Viadrid, 1955. 
que, difícilmente, se hubiese reconocido el origen común: unas veces por regularse reglamentariamente materias no previstas en la Ley de Bases, otras por una pretendida exigencia de la peculiaridad de la materia sobre que el procedimiento versaba. En todo caso, l'a anarquía reinante ponía claramente de manifiesto la necesidard de un nuevo Código de Procedimiento administrativo. Justificándola, decía el maestro Gascón y Marín : “Parece evidente que, dada la evolución que se ha operado en materia de procedimiento, las nuevas normas no previstas en la Ley de Bases, pero que acentadamente se han llevado a la reglamentación del procedimiento administrativo, tanto en la esfera de Administración local como en la de la central, se impone el ir a la promulgación de un Código único de procedimiento administrativo. La diversidad de materias sobre que versan las reclamaciones o peticiones formuladas por los particulares no deben llevar a la variedad de plazo, de denominaciones y naturaleza de recursos que se advierten en los Reglamentos en vigor" (24).

Resultaba lógico que las consideraciones anteriores se potenciasen durante los últimos meses, en que un clima en torno a la reforma administrativa ha ido surgiendo en nuestro país. En ta Semana de estudios sobre la reforma administrativa que tuvo lugar en Santanider en julio de 1957, uno de los temas de discusión fué justamente este del procedimiento administrativo. La crítica que allí se hizo de nuestro Derecho sobre la materia se concnetaba en las dos siguientes objeciones: en primer lugar, eran muchas las normas anquilosadas y sin fluidez (por exigir formalidades innecesarias, por establecer plazos lentísimos para la resolución de los expedientes, por anacronismos no corregidos, etc.); en segundo lugar, débil garantía del administrado (25). Partiendo de aquí, se ofrecían las bases para la reforma y simplificación del procedimiento, entre las que se contenían la propuesta de redacción de una nueva Ley que articula-

(24) Up. cit., pág.

(20) AGUIRre Loustao y Osorio Garcta, Simplificación del Procedimiento administrativo, en aPrimera Semana de estudios sobre la reforma administrativas, Madrid, 1958, pág.s. 81 y ss. 
se un texto uniforme de procedimiento administrativo (26). En estas circunstancias debe de considerarse como una feliz coincidencia el hecho de que la Sección de Administración Pública del Instituto de Estudios Políticos viniese desde hace tiempo trabajando en proyecto análogo y que, finalmente, recibiese de la Presidencia del Gobierno el encargo de colaborar oficialmente en la tarea.

\section{EXAMEN DE LA LEY}

6. La Ley sobre Procedimiento administrativo constituye un verdadero Código compuesto de 146 artículos, 8 disposiciones finales y una transitoria. Como ya advertimos antes, desborda con mucho el campo estricto del procedimieto para ser, realmente, una "Ley sobre la acción administrativa", pues tanto se reglamenta la forma como el fondo de ésta. A más de un título preliminar, en el que se determina el ámbito de aplicación de la Ley, se estructura en los siguientes seis títulos: título $1 .^{\circ}$, los órganos administrativos; título $2 .^{\circ}$, los interesados; títu'io $3 .^{\circ}$, actuación administrativa; título $4 .^{\circ}$, procedimiento; título $\mathbf{5 .}^{\circ}$, revisión de los actos en vía administrativa, y título $6 .^{\circ}$, procedimientos especiales. Se comprende que una tan amplia materia podria servir de argumento a una extensa monografía. Por eso, nos limitaremos aquí al examen de unos cuantos puntos que consideramos de la mayor importancia.

7. Ante todo ha de señalarse que no ha sido el punto de vista de la legalidad el único que ha preocupado a los redactores de la Ley. Importa que la acción administrativa se ajuste a la Ley y que la composición del interés público y de los intereses particulares se logre cabalmente a través de un procedimiento concebido como "forma de garantía jurídica". Pero importa también que la actuación administrativa sea eficaz $\mathrm{y}$, en este

(26) llaka Poz y Fernández Orts, Simplificación del Procedimiento admiaistrativo, en aPrimera Semana...p, cit., págs. 83 y ss. 
sentido, que el procedimiento administrativo constituya precisamente un vehículo de eficacia.

Ahora bien, lo que ya no se ve tan claro es hasta qué punto este resultado últimamente aludido se puede conseguir simplemente dictando normas jurídicas. ¿Qué valor práctico puede tener, por ejemplo, un precepto en el que se diga que la actuación administrativa tiene que ser lógica, rápida y eficaz (artículo 29), si luego realmente no lo es? Y por otra parte, : acaso no se puede conseguir tal resultado sin necesidad de hacer ingenuas declaraciones legales que necuerden más o menos aquella famosa exigencia constitucional que obligaba a los españoles «a ser justos y benéficos»?

Sin embargo, y no obstante esta suspicacia inicial, incluso en esta materia puede haber necesidad de una normativa jurídica en sentido estricto. John Clarke Adams nos recuerda en Tarsión italiana de su Derecho administrativo americano (Il Diritto amministrativo americano, Bolonia, 1957, pág. 11), que en el momento en que redacta sus lecciones se está discutiendo en el Parlamento italiano una Ley que permita utilizar para la confección de ciertos documentos públicos la máquina de escribir, en lugar de la redacción a mano con tinta permanente (27). Una finalidad análoga justifica el artículo 80 , donde se dice que clas notificaciones se realizarán mediante oficio, carta, telegrama o cualquier otro medio que permita tener constancia de la recepción y de i'a fecha". Igualmente tienen sentido jurídico las normas que tiendan a la uniformización del horario de despacho al público (art. 37) ; o de creación de oficinas de información encaminadas a facilitar las relaciones con el público de los órganos administrativos; o el precepto que dispone (art. 42) que cuando hayan de dictarse una serie de actos, todos ellos de la misma naturaleza (como nombramientos, concesiones o licencias), se

(27) En el sistema italiano -añade ADams- es necesario una nueva đey para modernizar una vieja norma dictada en una época que no conocía la maiquina de escribir; en cambio, en el sistema anglo-americano, para colmar esta diferencia de la norma, bastaria que el Tribunal declarase que, a los efectos de la Ley en cuestión, un acto mecanografiado con tinta permanente satisface las exigencias legales. Finalidad análoga cumple el anticulo 38 de la Ley. 
refundirán en un único documento, sólo el cual llevará la firma de la autoridad competente:

8. La Ley regula -y esto no es materia estrictamente procedimental - los principios generales sobre la competencia y su atribución a los órganos administrativos. Debe de destacarse el principio que se contiene en el artículo $5 .^{\circ}$ : "Si alguna disposición atribuye competencia a la Administración del Estado, sin especificar el órgano que debe ejercerla, se entenderá que la facultad de instruir y resolver los expedientes no corresponde a los órganos centrales, sino a los inferiores competentes por razón de la materia y del territorio; y de existir varios de éstos, la instrucción y la resolución se entenderá atribuida al órgano de competencia territorial más amplian. Esta declaración no deja de chocar - seguramente en atención a una aspiración desconcentradora- con principios que estaban en la base de nuestro Ordenamiento positivo, como la propia Jurisprudencia había declarado (28). En efecto, la atribución de competencias concurrentes (atribución genérica a un Departamento sin especificar el órgano concreto que, con exclusión de los demás, debe ejercitarla), debería permitir el juego del principio de jerarquía, informante, como reconoce el artículo $1 .^{\circ}$ de la Ley de Régimen jurídico, de nuestra organización administrativa. En su virtud, y salvo exclusión formal que realice la Ley, debería entenderse que el órgano superior puede avocar las competencias del inferior en orden a la incoación y tramitación de los expedientes administrativos. Pero el juego de este artículo con el $4 .^{\circ}$ parece hacer de la avocación no la regla, sino la excepción.

El afán desconcentrador del proyecto se manifiesta más acusadamente todavia en el artílculo $6 .^{\circ}$ que atribuye a las dependencias inferiores de los Departamentos civiles la facultad de "resolver aquellos asuntos que consistan en la simple confrontación de hechos o en la aplicación automática de normas, tales como libramiento de certificaciones, anotaciones o inscripciones,

(28) Esta doctrina fué sentada por la jurisdicción de agravios. Así: Orden de la Presidencia de 25 octubre de 1951 ( $\propto$ B. O. del E.» de 5 de noviembre). 
así como instruir los expedientes, cumplimentar y dar traslado de los actos de las autoridades ministeriales, diligenciar títulos, autorizar la devolución de documentos y remitirlos al archivon.

Con el nombre de "conflictos de atribuciones" la Ley regula los problemas positivos y negativos de atribución de competencias que pueden surgir entre órganos pertenecientes a un mismo Departamento ministerial: los negativos en el artículo $8 .^{\circ} \mathrm{y}$ los positivos en los artículos 17 a 19 . Se ha simplificado convenientemente el complicado procedimiento que se inciuía en el proyecto de Ley enviado a las Cortes, cuya crítica tuvimos la oportunidad de realizar públicamente en conferencia pronunciada en la Academia de Jurisprudencia y Legislación.

9. Por primera vez en nuestro Derecho, una Ley viene a regular de modo completo toda la teoría del acto administrativo $\mathrm{y}$ de los supuestos de invalidez.

a) De acuerdo con el artículo 40, se consideran como elementos esenciales de los actos de la Administración la competencia, la causa, motivo y fines y el procedimiento. El propio artículo, ail declarar que "el contenido de los actos se ajustará a lo dispuesto en el Ordenamiento jurídico y será adecuada a los fines de aquéllos", abre ta puerta a la posibilidad de fiscalizar los actos administrativos irregulares por "desviación de poder", confirmándose asi lo ya previsto en el número 2 del artículo 33 de ila Ley sobre la Jurisdicción contencioso-administrativa de $\mathbf{1 9 5 6 .}$ Los artículos 48 y 111 de la Ley de Procedimiento vuelven con una expresa referencia a la udesviación de poder".

En materia de motivación, la Ley, en cambio, no esi rigurosa. En primer lugar, comienza por desterrar la forma tradicional de los resultandos y considerandos que, en tantos expedientes administrativos, constituye actualmente la regla de nuestro Derecho (art. 93, núm. 2). En segundo lugar, limita la obligación de motivar a aquellos actos (art. 43) que restrinjan derechos subjetivos, que resuelvan recursos, que se separan del criterio seguido anteriormente o del dictamen de los órganos consultivos $o$, finalmente, que lo exijan disposiciones legales o que decreten la suspensión de actos recurridos. 
Además, se excluyen totalmente de la obligación de motivạs los actos de policía sobre la prensa, radio, cinematografía y teatro.

Creo que estos criterios son erróneos. La obligación de motivar debe constituir la regla, pues incluso en los casos en que la resolución es beneficiosa para el particular que la suscitó, conviene advertir, para conocimiento de todos, los motivos que la justifican como no contraria a la legalidad ni al interés público. Por otra parte, entiendo -y creo que estará conmigo quien tenga una mínima experiencia administrativa - que el obligar a que ciertas resoluciones se dicten bajo la forma de antecedentes o resultandos. y considerandos, constituye el sistema óptimo para que los expedientes sean estudiados a fondo por el funcionario encargado de proponer su resollución. Es muy frecuente que la impresión de conjunto que un funcionario tenga respecto de un expediente, sea modificada o corregida justamente en el momento en que tiene que redactar los resultandos y considerandos de su nota-propuesta, pues la disciplina lógica y mental que este sistema impone, implica una evidente garantía de justicia que no debe, como norma, sacrificarse en aras de una pretendida mayor rapidez administrativa.

b) Constituye, a' nuestro juicio, un auténtico logro el tratamiento que la Ley realiza de los supuestos de invalidez de los actos administrativos. Por primera vez se realiza una distinción con relevancia legal entre los casos de nulidad de pleno derecho (art. 47) y de anulabilidåd (art. 48). Son nulos de pleno derecho los actos de la Administración en los casos siguientes: los dictados por órgano absolutamente incompetente; los de contenido imposible o contrario a la Ley penal y los dictaidos prescindiendo total y absolutamente de los procedimientos establecidos (vía de hecho) o de las normas esenciales para la formación de la voluntad de los órganos colegiados. Asimismo se consideran nulas de pleno derecho las disposiciones administrativas de carácter general que infrinjan los limites impuestos a la potestad reglamentaria por los artículos 23 a 27 de la Ley de Régimen jurídico. Ni que decir tiene que nos mostramos absolutamente de acuerdo con esta enumeración que coincide sus- 
tancia!mente con la por nosotros realizada -creemos que por primera vez en la doctrina- en nuestro libro Régimen de impugnación de los actos administrativos (29).

10. Otra novedad de la Ley está constituída por la regulación que se hace de la ejecución de los actos administrativos. No se trata aquí simplemente de declarar el principio de ejecutividad de l'os actos administrativos; sino que el problema que aquí se aborda es el de la llamada "acción administrativa de oficion, y que no es otra cosa que el conjunto de medios de que la Administración dispone para compeler a los particulares al cumplimiento de las obligaciones administrativas. Después de sentarse el principio fundamental de que la Administración pública no puede emprender ninguna actuación material que lesione o perturbe los derechos e intereses de los particulares sin que previamente haya sido adoptada la decisión que le sirve de fundamento jurídico (art. 100), se determinan los siguientes medios de ejecución forzosa: $a$ ), apremio sobre el patrimonio; $b$ ), ejecución subsidiaria ; $c$ ), compulsión sobre las personas, y $d$ ), multa coercitiva. Así como algunos de estos procedimientos han sido tradicionalmente regulados por nuestro Derecho, como es el caso dell apremio sobre el patrimonio para lo que basta una remisión al Estatuto de Recaudación, en otros casos todo intento de regulación tenía que resultar particularmente delicado y así, y en relación con la compulsión sobre las personas, la Ley tiene que limitarse a decir que "los actos administrativos que impongan a los administrados una ob.igación personalisima de no hacer o soportar, podrán ser ejecutados por compulsión directa sobre sus personas en los casos en que la Ley expresamente lo autorice $\mathrm{y}$ dentro siempre del respeto debido a la dignidad de la persona humana y a los derechos reconocidos en el Fuero de los Españoles" (art. 108).

(29) El art. 23 de la Ley de Régimen juridico dice: eNinguna disposición administrativa podrá vulnerar los preceptos de otra superiors. Predicar la nulidad atsoluta para las ilegalidades derivadas de este precepto puede tener consecuencias iticalculables. A pesar de la tajante afirmación del articulo 47,2 de la Ley de Procedimiento, entendiendo que aqui la Jurisprudencia tendrá mucho que matizar. 
Como es natural, en la Ley no se tratá de los medios especiales (como el empleo de la fuerza púbíica) de que la Administración dispone en ejercicio de sus funciones de policía de seguridad por razón de orden público.

11. Por lo que se refiere a' procedimiento propiamente dicho, la Ley significa run notable intento de simplificación y aceleramiento de la actividad administrativa. En relación con la recepción y registro de documentos, se contiene la innovadora regla de que los Gobiernos civiles se convierten en $\mathrm{Re}$ gistros generales de recepción de cualquier tipo de documento o instancia dirigido por un particular a órgano del Estado radicante en otra provincia. Mayor trascendencia práctica tiene aún la norma (art. 66, núm. 3) que habilita a las oficinas de Correos para recibir instancias y documentos dirigidos a centros o dependencias administrativas, siempre que se presenten en sobre abierto para ser fechados y sellados por el funcionario de Correos antes de ser certificados, entendiéndose que dichos documentos han tenido entrada en la Administración a partir de la fecha del sello de la oficina de Correos. Asimismo se admite el uso del giro postal para el pago de tasas administrativas (art. 64, 4, in fine).

De generosa, al mismo tiempo que ambiciosa, debe de calificarse la norma (art. 39) que intenta reducir a un único expediente, asuntos en los que actualmente intervienen con facultades decisorios dos o más Departamentos ministeriales u organismos administrativos. El administrado recibirá ciertamente con júbilo esta disposición. Se trata de evitar, por ejemplo, que en la matriculación de un coche o en la apertura de una nueva industria, el particular haya de peregrinar de organismo en organismo obteniendo sucesivas autorizaciones y permisos, todos ellos igualmente necesarios para lograr el resultado final. La solución arbitraria por la Ley es la siguiente: en tales casos el expediente se iniciará y resolverá en el centro directivo o $\mathrm{Mi}$ nisterio que tenga una competencia más específica en relación con el objeto de que se trate; este centro o Departamento recabará de los otros a los que competa algún género de intervención en el asunto, cuantos informes o autorizaciones sean 
precisos; se entenderá que no existe objeción cuando transcurra un mes sin recibir respuesta del Ministerio consultado; si se trata de informes o remisión de datos necesarios para la resolución del expediente, el transcurso de un mes sin que sean remitidos por el funcionario obligado a ello, determinará su responsabilidad (art. 39).

Sin embargo, y no obstante su buena voluntad, el efecto práctico de este precepto está aún por demostrar. Desde luego, es muy molesito para el particular -y gracias a esto viven tantas y tantas gestorías privadas- entenderse simultáneamente con diversos organismos administrativos. Pero cuando hacen falta diversas autorizaciones administrativas como condicionantes de una resolución final, el celo que normalmente guía la actividad privada, hace que estos expedientes administrativos parciales ise pongan en marcha simultáneamente, cosa que será imposible con el nuevo sistema, donde cada uno de ellos quedará convertido en una fase integrativa de un procedimiento más general. Piénsese, por ejemplo, en lo que ahora representa obtener un pasaporte para salida al extranjero. Aparte de la presentación de los documentos que pudiésemos llamar clásicos, como partida de nacimiento y certificado negativo de antecedentes penales (que, por cierto, no queda muy claro después del precepto que comentamos si debieran conceptuarse como momentos integrativos, y a obtener de oficio, del expediente genera!), es necesario acreditar otras autorizaciones previas, como la militar (los que aún no han pasado a reserva absoluta), la jerárquica (los pertenecientes a cualquier Cuerpo del Estado), certificado de Servicio Social en la mujer, etc.; pues bien, ¿si todos éstos pasan a ser trámites de un expediente único, el resultado será abreviarlo o alargarilo? La propia Ley ha advertido el peligro al dejar a salvo, en cualquier caso, la posibilidad de que el propio interesado obtenga por sí estos informes y certificados.

En cualquier caso, to que no debe negarse es que la preocu. pación de la Ley es la abreviación de los plazos. Así, se prescribe que, a no mediar causas extraordinarias, "no podrá exceder de seis meses el tiempo que transcurra del día en que se inicie un procedimiento administrativo, hasta aquel en que se 
dicte resolución" (art. 61). El retraso implicará la responsabilidad disciplinaria del funcionario culpable de la demora.

Esta cuestión de los plazos debe de relacionarse co'l el problema del silencio administrativo.

La Ley repite (art. 94), incluso con las mismas pa!abras, e! precepto contenido en el artículo 38 de la Ley sobre la Juisdicción contencioso-administrativa de 27 de diciembre de 1956. Como se sabe, aquí se sienta el principio de que el transcurso de un determinado plazo sin que la Administración resuelva una cuestión que se le hubiese planteado, implica la presuncióni de una resolución negativa, recurrible, por tanto, por el particular afectado. Ahora bien, la teoría general del silencio administrativo se completa en la nueva Ley con la admisión de dos supuestos en los que el silencio se entenderá positivo. Son éstos, los siguientes (art. 99) : a) los que expresamente se establezcan por disposiciones especiales, refrendándose asi las ya existentes en este sentido; por ejemplo, las licencias y permisos a que se refiere el artículo $9 .^{\circ}$, números $5 .^{\circ}$ y $7 .^{\circ}$ del Reglamento de Servicios de las Corporaciones locales ; $b$ ) autorizaciones o aprobaciones que deban otorgarse por los órganos de la Administración en ejcrcicio de sus funciones de fiscalización y tutela sobre los órganos inferiores.

12. La Ley dedica cuatro artículos al problema de la revisión de oficio por la Administración de sus propios actos en vía administrativa. La distinción, a que en su momento a'udidimos, entre nulidad absoluta y anulabilidad, va a tener aquí sus consecuencias, pues cuando se trate de aquélla, se concede facultad a la Administración para declarar, previo dictamen favorable del Consejo de Estado, en cualquier momento la nulidad de dichos actos.

Respecto de los demás actos anulables, la Ley, reiterando la novedad que ya supuso el artículo 37 de la Ley de Régimen jurídico de la Administración, viene a distinguir entre "actos que infringen manifiestamente la Ley, según dictamen del Consejo de Estadon y actos cuya ilega'idad, podríamos decir, sea más leve (es decir, no manifiesta). Los primeros pueden ser anulados de oficio, siempre que no hayan transcurrido cuatro años; 
en cambio, respecto de los segundos, subsiste el clásico proceso de lesividad que exige, después de una declaración en tal sentido, que la Administración impugne sus propios actos ante la Jurisdicción contencioso-administrativa. Como se ve, el ámbito de este proceso queda ahora notablemente reducido. con lo que se abre una brecha - por otra parte necesaria- a uno de los más característicos principios del Derecho administrativo español.

Con independencia de lo anterior, el proyecto enviado a las Cortes abria también la posibilidad de la revocación, por motivos de oportunidad, de actos administrativos válidos y declara. torios de derechos, aplicando el procedimiento de la expropiación forzosa. Esta posibilidad no era sino una lógica consecuencia del ámbito que en nuestro actual Ordenamiento tiene el instituto de la expropiación, de acuerdo con la Ley de $\mathbf{1 6}$ de diciembre de 1954. Ahora bien, tal precepto ha desaparecido de la redacción legal definitiva, si bien aún resta -como vestigio- una alusión a la revocación (art. 112) que ahora carece de sentido.

13. La vieja Ley de Procedimiento administrativo de $\mathbf{1 8 8 9}$ sentaba en sus bases 12,13 y 14, los principios para la regulación de los siguientes recursos: alzada, queja, incompetencia y nulidad. A estos dos últimos les calificaba de "extraordinarios". Si contrastamos esta enumeración con la que se hace en la nueva Ley-donde sólo se regui"an recursos de alzada, reposición y revisión- nos daremos cuenta de que la discrepancia es notab!e. Y así tiene que ser, supuesta, en primer lugar, la falta de técnica que en esta materia presidió la Ley de 1889, y, en segundo lugar, las correcciones que a la propia Ley habían hecho los más modernos Reglamentos de Procedimiento administrativo.

En efecto: el recurso de reposición (desconocido en la vieja Ley) se introdujo primero en nuestra legisiación local, más tarde con carácter extraordinario en la esfera central y, finalmente; como recurso ordinario y trámite normal previo a la via contencioso-administrativa después de la nueva Ley sobre esta Jurisdicción (art. 52) ; los recursos de incompetencia o de nulidad por vicio de forma, carecian de sustantividad propia, pues 
tanto la incompetencia como el vicio procedimental son sencillamente posibles motivos en que fundar el recurso ordinario de alzada; por último, el recurso de queja contra defectos en la tramitación de un expediente ya había sido atacado por la doctrina, que le negaba precisamente el carácter de recurso, puesto que - se decía- el recurso supone siempre un acto administrativo que impugnar, y en estos casos justamente lo que falta es el acto administrativo (criterio aceptado por el Reglamento del Ministerio de la Gobernación de 1947 , que no habla de recurso sino de "escrito de queja").

La Ley refleja, pues, en este punto, el' estado actual de la doctrina. Excluída 1a queja (cuya reglamentación pasa a hacerse en el capítulo dedicado a la tramitación del procedimiento administrativo, art. 77), y remitiéndose, por lo que al recurso de reposición toca, a lo ya establecido en la Ley de la Jurisdicción contencioso-administrativa, sólo se va a prestar una atención especial al recurso ordinario de alzarda y al extraordinario de revisión contra actos administrativos firmes. En cuanto al recurso de súplica o alzada ante el Consejo de Ministros o ante la Presidencia del Gobierno, sólo se admite cuando esté expresamente reconocido por una disposición especial.

Por lo demás, en esta materia no se descubren grandes innovaciones. Sólo se nos ocurre llamar la atención sobre los tres siguientes extremos:

a) El artículo 119 prescribe que "la autoridad que resuelv? el recurso, decidirá cuantas cuestiones plantee el expediente, hayan sido o no alegadas por los interesados" (30). ¿ Debe descubrir aqui la base jurídica que habilita a la Administración para dictar una resolución del recurso que implique una reformatio in peius? Sinceramente creemos que hay argumentos en pro y en contra para mantener esta solución. En contra, se puede alegar que toda reformatio in peius implica revocación de un acto administrativo declaratorio de derechos, y la única forma de lo-

(30) Precepto análogo se contiene en el art. 5.\%, párrafo 3.०, del Reglamento de Procedimiento económico-administrativo de 1924. 
grar esta finalidad - de acuerdo con el propio sistema que ya hemos visto establece este proyecto de Ley- es la declaración de lesividad o, en los casos de ilegalidades manifiestas, la iniciación de un expediente en que es preceptiva la audiencia del' Consejo de Estado. Pero frente a esto, puede cabalmente aducirse la existencia del propio precepto que examinamos que, o ha venido a conceder tales poderes, o caso contrario, debe de considerarse superfluo y carente de sentido.

b) El segundo punto se refiere al artículo 113, número 2, que dice: "Los recursos contra un acto administrativo que se funden únicamente en la ilegalidad de alguna disposición administrativa de carácter general, podrán interponerse directamente ante el órgano que dictó dicha disposición". Su simple lectura evidencia su fundamento.

c) Finalmente, debe subrayarse la disposición del' artículo 120, según el cual la estimación de un recurso contra disposición general comporta la derogación o modificación de ésta, sin perjuicio de que subsistan los actos furmes dictados en su aplicación (31).

14. Tres son los procedimientos especiales que regula la Ley: el procedimiento para la elaboración de disposiciones de carácter general, el procedimiento sancionador y el procedimiento en las recliamaciones previas a la vía jurisdiccional civil. Por su novedad, es el primero de ellos el que va a merecer nuestra atención.

Ninguna norma de nuestro Derecho vigente - salvo el preceptivo informe del Consejo de Estado en ciertos casos- establece requisitos procedimentales para la emisión de reglamentos o disposiciones administrativas de carácter general. Esta situación determina, obviamente, una extraordinaria agilidad en el uso de esta potestad administrativa, pero no deja de tener sus inconvenientes: el Boletín Oficial del Estado es testigo con frecuencia de las modificaciones a que son. sometidas tantas disposiciones de carácter general de muy reciente vigencia, simplemen-

(31) He aqui cómo la propia Ley amortigua los terribles efectos de la nulidad absoluta a que nos referimos en la nota 29. 
te porque el órgano que las dictó no tuvo en cuenta una sugerencia o un punto de vista que con una elaboración más meditada no se hubiese escapado.

La Federal Administrative Procedure Act norteamericana de 1946 establece ya un detallado procedimiento para la adopción de las Regulations, que comienza con la necesidad que se impone a la Administración de publicar su propósito reglamentista y los puntos concretos que serán afectados por la nueva disposición, al objeto de oír los puntos de vista de los interesados. Creo que algo de esto había que hacer entre nosotros, y a ello se refieren los artículos 129 a 133 de la Ley. La elaboración sa realizará ahora de acuerdo con los siguientes trámites:

a) Formación de expediente en el que, junto con la moción, providencia o propuesta de quien tenga la iniciativa reg'amentaria, figurarán las consultas y dictámenes evacuados, 1as enmiendas y observaciones, y demás datos de interés (art. 129, 1 y 2);

b) Se preparará una tabla de vigencias y de disposiciones derogadas por la que se proyecta (art. 129, 3);

c) Habrá de informar la Secretaría General técnica o, en su defecto, la Subsecretaría, o el Estado Mayor en los Ministerios militares (art. 130);

d) Habrá de requerirse la aprobación de la Presidencia del Gobierno cuando se trate de materias sobre estructura orgánica, métodos de trabajo, procedimiento y personal (art. 130, 2, en relación con el art. 13, 7 de la Ley de Régimen jurídico);

e) En los casos que proceda, deberá oírse a la Organización sindical u Organizaciones que representen intereses generales o corporativos (art. 130,4);

f) Cuando su natura'eza lo aconseje, el proyecto se someterá a información pública (art. 130, 5); y

g) Las disposiciones que hayan de aprobarse en Consejo de Ministros se comunicarán a todos los Ministros con ocho días de antelación (art. 131). 